\title{
COMPUTATION-GUIDED MULTIFUNCTIONAL DESIGN OF STRUCTURAL BATTERY COMPOSITES
}

\author{
$\underline{\text { David Carlstedt }}^{{ }^{*}}$, Kenneth Runesson ${ }^{1}$, Leif E. Asp ${ }^{1}$ \\ ${ }^{1}$ Department of Industrial and Materials Science, Chalmers University of Technology, Sweden \\ *david.carlstedt@chalmers.se
}

A viable solution to improve the efficiency of future electric vehicles and devices is to utilize structural battery composites [1,2]. This material is made from carbon fibre reinforced polymer and has the ability to store electrical energy (i.e. work as a battery) and carry mechanical loads, simultaneously. Recently, the authors $[3,4]$ developed a computational modelling framework to study the electro-chemo-mechanical properties of structural batteries while allowing for twoway coupling between the electro-chemical and mechanical fields (Figure 1a). In this work, a novel design strategy for computation-guided multifunctional design of structural battery composites is presented. We utilize a previously developed computational modelling framework [3, 4] and demonstrate how this framework can be used as a tool to evaluate the multifunctional performance of different material designs (Figure 1b). Moreover, parametric studies are performed to identify critical design parameters and evaluate the criticality of coupling terms.

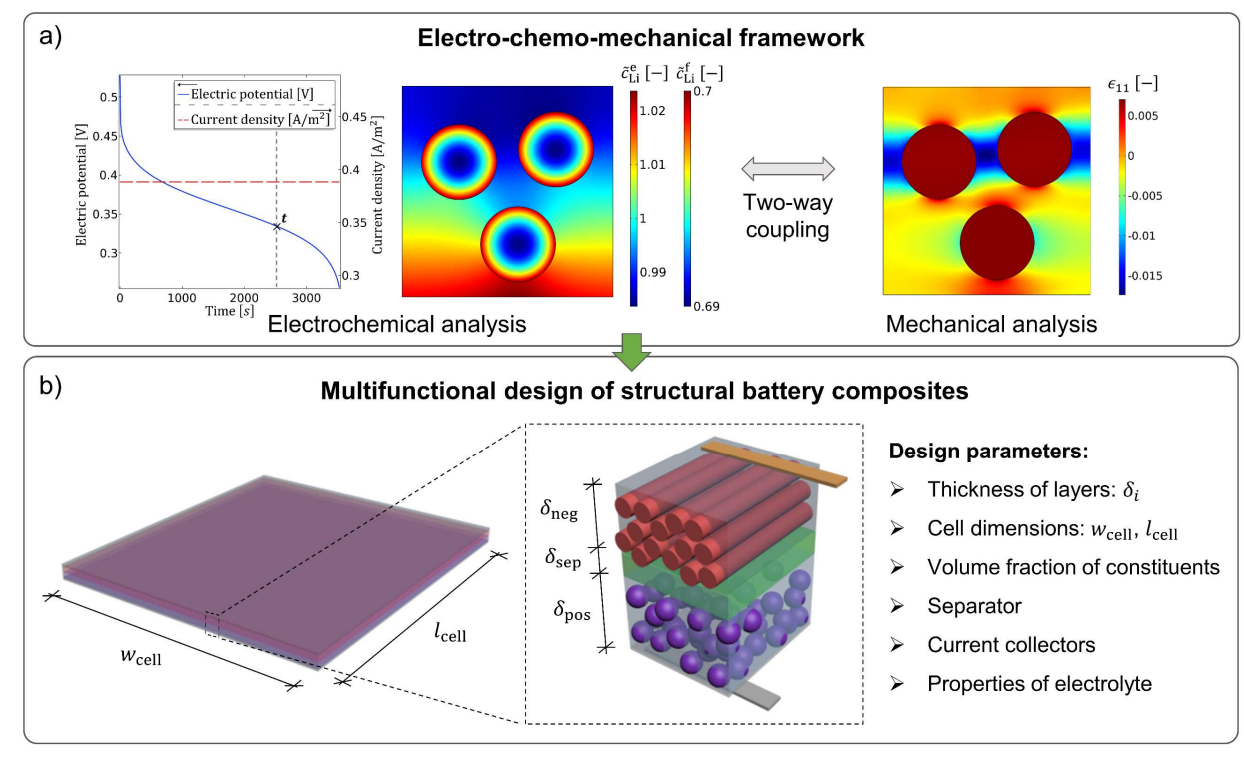

Figure 1. (a) A computational framework, developed by the authors [3, 4], is extended and utilized to (b) study the multifunctional performance of structural battery composite designs.

\section{References}

[1] L.E. Asp et al. (2021) A structural battery and its multifunctional performance. Advanced Energy and Sustainability Research, 2000093.

[2] D. Carlstedt, L.E. Asp (2020) Performance analysis framework for structural battery composites in electric vehicles. Composites Part B, 186, 107822.

[3] D. Carlstedt, K. Runesson, F. Larsson, J. Xu and L.E. Asp (2020) Electro-chemomechanically coupled computational modelling of structural batteries. Multifunctional Materials, 3, 045002.

[4] D. Carlstedt, K. Runesson, F. Larsson, V. Tu, R. Jänicke, and L.E. Asp, Computational modelling of structural batteries accounting for stress-assisted convection in the electrolytes. Submitted for publication. 